\title{
Intracellular antioxidant activity of Muntingia calabura leaves methanolic extract
}

\author{
AULIA NUR RAHMAWATI ${ }^{1, \boldsymbol{v}}$, OKID PARAMA ASTIRIN ${ }^{1,2, \boldsymbol{v}}$, ARTINI PANGASTUTI ${ }^{1,2}$ \\ ${ }^{1}$ Bioscience Graduate Program, Universitas Sebelas Maret. Jl. Ir. Sutami 36A, Surakarta 57126, Central Java, Indonesia, Tel./fax. +62-271-663375, \\ "email: aulianur1293@gmail.com \\ ${ }^{2}$ Department of Biology, Faculty of Mathematics and Natural Sciences, Universitas Sebelas Maret. Jl. Ir. Sutami 36A, Surakarta 57126, Central Java, \\ Indonesia, Tel./fax. +62-271-663375, ${ }^{*}$ email: parama_astirin@yahoo.com
}

Manuscript received: 17 June 2018. Revision accepted: 4 September 2018.

\begin{abstract}
Rahmawati AN, Astirin OP, Pangastuti A. 2018. Intracellular antioxidant activity of Muntingia calabura leaves methanolic extract. Nusantara Bioscience 19: 210-214. Excessive reactive oxygen species (ROS) results in oxidative damage that destroys proteins, lipids, and DNA, resulting in various diseases and accelerating the aging process. Antioxidants are compounds that have the ability to suppress oxidative stress. Muntingia calabura has a high phytochemical content, especially the phenolic group that can act as antioxidant. This study aimed to determine the intracellular antioxidant activity of $M$. calabura leaves methanolic extract (MLME) through intracellular ROS levels in 3T3 fibroblast cells under normal condition and oxidative stress due to UVB exposure. Tests were performed using the DPPH (Diphenyl-1-picrylhydrazyl) method and modified NBT (Nitroblue Tetrazolium). Testing of antioxidant activity with DPPH method obtained result that MLME had high antioxidant activity with $\mathrm{IC}_{50}$ value of $3.030 \mu \mathrm{g} \mathrm{mL}^{-1}$, while intracellular antioxidant activity with modified NBT method showed that MLME statistically had significant effect on intracellular ROS level under normal condition $(p<0.05)$ based on dose-dependent manner, but not significant $(p>0.05)$ under oxidative stress condition. Significant effects were only shown at a concentration of $20 \mu \mathrm{g} \mathrm{mL}^{-1}$ against the control of oxidative stress due to UVB exposure.
\end{abstract}

Keywords: Antioxidant, Intracellular ROS, NBT, Muntingia calabura

\section{INTRODUCTION}

Reactive oxygen species (ROS) including superoxide anion $\left(\mathrm{O}_{2}{ }^{-}\right)$, hydroxyl radical $\left(\mathrm{OH}^{*}\right)$ and hydrogen peroxide $\left(\mathrm{H}_{2} \mathrm{O}_{2}\right)$ are products of cellular metabolic activity and serve as second messengers in the cell signaling process when encountered in sufficient quantities. The presence of ROS in high concentrations has a harmful effect on cells because it destroys proteins, lipids, and DNA (Bhattacharryya et al. 2014; Rinnerthaler et al. 2015; Sarangarajan et al. 2017). An increase in the number of ROS occurs in response to UV exposure, cigarette smoke, alcohol consumption, pathogen infection and other external factors that lead to oxidative stress (Bhattacharryya et al. 2014). Oxidative stress that results in oxidative damage is the beginning of many diseases and is included in the main factors that accelerate the aging process (Guerra-Araiza et al. 2013; Pisoschi and Pop 2015; Valko et al. 2016).

Oxidative stress is naturally inhibited by enzymatic antioxidant compounds such as superoxide dismutase, catalase, and glutathione peroxidase, as well as nonenzymatic antioxidant compounds such as glutathione, alpha-tocopherol, ascorbic acid and ubiquinone (Bhattacharryya et al. 2014). However, the high oxidative stress in the cells can cause a disruption of the balance between the amount of ROS with endogenous antioxidants, thus disrupting oxidative homeostasis (Jadoon et al. 2015; Poprac et al. 2017). Exogenous antioxidants help increase oxidative homeostasis through increased endogenous antioxidant activation and direct ROS stabilization (Guerra-
Araiza et al. 2013; Nakchat et al. 2014; Jadoon et al. 2015). Exogenous antioxidants can be found as natural antioxidants which are the way out for oxidative stress management because they can affect endogenous antioxidant systems and balance oxidative homeostasis (Jadoon et al. 2015). The search for natural antioxidant sources led to arise of various studies related to phytochemical and antioxidant, including Muntigia calabura.

Muntigia calabura or 'kersen' (in Bahasa Indonesia) is a plant of the Elaeocharpaceae family encountered in almost all tropical regions due to its high adaptability (Lim 2012; Mahmood et al. 2014). M. calabura has been widely used in Peru, Colombia, Mexico, Vietnam and the Philippines to reduce ulcers, fever, headaches, to be utilized as tranquilizers. M. calabura fruit is often consumed directly, and its leaves can be utilized as a substitute for tea (Mahmood et al. 2014). The high phytochemical content of M. calabura leaf extract, especially flavonoids and polyphenols causes the leaf extract of M. calabura to have antioxidant activity (Zakaria et al. 2011, 2014a; Balan et al. 2015), antiproliferative (Zakaria et al. 2011), antinociceptive (Zakaria et al. 2014a), anti-inflammatory (Balan et al. 2015), and anticarcinogenic (Nasir et al. 2017). The results of the test with DPPH radical scavenging activity showed that $M$. calabura leaf extract has antioxidant activity above $90 \%$ (Zakaria et al. 2011, 2014a; Balan et al. 2015) causing $M$. calabura to potentially as a source of natural antioxidant in the future. However, the effect of $M$. calabura leaf extract on intracellular ROS is unknown. 3T3 
fibroblast cells are used as an object because it is easy to culture and produce extracellular matrix (ECM) proteins (Freshney 2010), making it appropriate for research on oxidative damage caused by oxidative stress.

This study aimed to determine the antioxidant activity of $M$. calabura leaves methanolic extract on $3 \mathrm{~T} 3$ fibroblast cells under normal condition and oxidative stress due to UVB exposure using modified NBT.

\section{MATERIALS AND METHODS}

\section{Plant material and preparation of Muntingia calabura leaves methanolic extract}

Muntingia calabura leaves were collected in OctoberNovember 2017 from Wonorejo Village, Polokarto, Central Java, Indonesia. Extraction of $M$. calabura leaves was performed by maceration using $\mathrm{MeOH}$ based on Zakaria et al. (2014a, b) and Balan et al. (2015). M. calabura mature leaves had been grounded into fine powder after air-drying for about two weeks and as much as $100 \mathrm{~g}$ of fine powder was soaked in $\mathrm{MeOH}$ at a ratio of 1:20 (w/v) for $72 \mathrm{~h}$. The mixture was filtered with filter paper and evaporated using a rotary evaporator at $40^{\circ} \mathrm{C}$ to obtain a $M$. calabura leaves methanolic extract (MLME).

\section{Determination of total phenolic content}

Determination of total phenolic content (TPC) was performed using Folin-Ciocalteu method based on Singleton et al. (1999) with slight modification. A total of $300 \mu \mathrm{L}$ of MLME $(0.5 \mathrm{mg} / 1 \mathrm{~mL})$ was mixed with $1.5 \mathrm{~mL}$ of Folin-Ciocalteu reagent $10 \%$ and then incubated for 1 minute at room temperature. The mixture was added 1.2 $\mathrm{mL}$ of $\mathrm{Na}_{2} \mathrm{CO}_{3}$ and incubated at room temperature for 90 min. Absorbance was measured using a UV-Vis Spectrophotometer at $760 \mathrm{~nm}$. The absorbance measuring results were calibrated to the standard curve obtained from the absorbance of gallic acid with a concentration of 20,40 , 60,80 , and $100 \mu \mathrm{g} \mathrm{mL} \mathrm{m}^{-1}$.

\section{Thin layer chromatography}

Thin layer chromatography (TLC) was performed by using chloroform: ethyl acetate (40:60) as a mobile phase (eluent) and silica plate as a stationary phase. MLME (1 $\mathrm{mg} / 100 \mu \mathrm{L})$ which had been dissolved in methanol: ethyl acetate $(60: 40)$ was bottled on a silica plate. The silica plate with MLME was air-dried and then inserted into the eluent. Eluent was allowed to move along the silica plate until it reached a distance of $1 \mathrm{~cm}$ before the end of the plate. Quercetin $(1 \mathrm{mg} / 100 \mu \mathrm{L})$ was used as a comparison. The TLC results were exposed to ammonia vapor and seen under UV light at $254 \mathrm{~nm}$.

\section{Determination of antioxidant activity}

Determination of antioxidant activity was performed using the DPPH (Diphenyl-1-picrylhydrazyl) method based on Zakaria et al. (2014b) and Balan et al. (2015) with slight modification. A total of $50 \mu \mathrm{L}$ samples with various series concentrations were mixed with $50 \mu \mathrm{L}$ DPPH $0.1 \mathrm{mM}$. The concentration series used were $0,15.625,31.25,62.5,125$,
250 , and $500 \mu \mathrm{g} \mathrm{mL}^{-1}$. The mixture was incubated at room temperature for 30 minutes in the dark room. Absorbance was measured using BioRad Microplate Reader at $517 \mathrm{~nm}$. Antioxidant activity was known based on the formula according to Jemli et al. (2016):

$$
\% \text { inhibition }=\left(\frac{A O-A 1}{A O}\right) \times 100 \%
$$

$A_{0}$ is the absorbance of the control, while $A_{1}$ is the absorbance of the sample. The percentage of inhibition was used to determine $\mathrm{IC}_{50}$ value of antioxidant activity through a regression equation.

\section{T3 fibroblast cell culture}

3T3 fibroblast cell-line was cultured in complete media consisting of DMEM (Gibcoß) and FBS (Gibco®). Cells with a density of $7 \times 10^{3}$ were distributed into 96 wellplates and then incubated in a $\mathrm{CO}_{2}$ incubator for $24 \mathrm{~h}$ at 37 ${ }^{\circ} \mathrm{C}$ to let cells stick at the bottom of the plate.

\section{Cell viability assay}

Cell viability assay was performed using MTT (3-(4,5dimethylthiazol-2-yl)-2-5-diphenyltetrazolium) method in $3 \mathrm{~T} 3$ fibroblast normal cells. Culture media was discarded and replaced with complete medium that had been mixed with samples in DMSO. Variations in sample concentration used were $3.906,7.813,15.625,31.25,62.5,125,250,500$, and $1000 \mu \mathrm{g} \mathrm{mL}^{-1}$. The culture was incubated for $24 \mathrm{~h}$ at $37^{\circ} \mathrm{C}$ in $\mathrm{CO}_{2}$ incubator. The culture medium was removed and $100 \mu \mathrm{L}$ of MTT reagent $\left(0.5 \mathrm{mg} \mathrm{mL}^{-1}\right)$ was added. The culture was incubated for $4 \mathrm{~h}$ in the $\mathrm{CO}_{2}$ incubator at $37^{\circ} \mathrm{C}$ and $100 \mu \mathrm{L}$ SDS Stopper was added. The culture was incubated at room temperature for overnight under closed conditions of light. The absorbance measuring was performed using Bio-Rad Microplate Reader at $595 \mathrm{~nm}$.

\section{UVB irradiation and treatment}

3 T3 fibroblast cell-line culture with a density of $5 \times 10^{3}$ distributed into 96 well-plates for subsequent incubation in a $\mathrm{CO}_{2}$ incubator for $24 \mathrm{~h}$ at $37^{\circ} \mathrm{C}$. Culture media was discarded and replaced with complete medium that had been mixed with samples in DMSO. Variations in sample concentration used were 5,10 , and $20 \mu \mathrm{g} \mathrm{mL}^{-1}$. The culture was incubated overnight, then replaced with a new medium for further exposure of UVB light at a dose of $50 \mathrm{~mJ} \mathrm{~cm} \mathrm{~cm}^{-2}$ using the UVB irradiation system. The culture was incubated at $37^{\circ} \mathrm{C}$ for $48 \mathrm{~h}$ in the $\mathrm{CO}_{2}$ incubator.

Table 1. The percentage inhibition of DPPH activity by MLME

\begin{tabular}{lc}
\hline Concentrations $(\boldsymbol{\mu g} / \mathbf{m L})$ & \% inhibition of DPPH \\
\hline 0 & 0 \\
15.625 & 47 \\
31.25 & 60 \\
62.5 & 80 \\
125 & 81 \\
250 & 82 \\
500 & 80 \\
\hline
\end{tabular}

Note: The percentage inhibition of DPPH activity showed the potential of the MLME to scavenge DPPH free radical through in vitro assay. 


\section{Intracellular ROS assay}

Intracellular ROS assay was performed using a modified NBT (Nitroblue Tetrazolium) methods based on Tunc et al. (2008) and Adrian et al. (2013). The culture that had been incubated for $48 \mathrm{~h}$ was rinsed with $100 \mu \mathrm{L}$ PBS, then given $100 \mu \mathrm{L}$ of NBT in PBS. The culture was incubated at $37^{\circ} \mathrm{C}$ for 45 minutes and rinsed with $100 \mu \mathrm{L}$ PBS twice. The culture was dried and then dissolved with $60 \mu \mathrm{L} \mathrm{KOH} 2 \mathrm{M}$ and $140 \mu \mathrm{L}$ DMSO. Samples were allowed to stand for 10 minutes before an absorbance measuring at $450 \mathrm{~nm}$ wavelength was performed.

\section{Data analysis}

Data analysis was performed using Microsoft Excel 2010. One-way ANOVA and Tukey-Kramer post hoc test were used to evaluate the significance $(p<0.05)$ between samples and controls.

\section{RESULTS AND DISCUSSION}

\section{Total phenolic content and thin layer chromatography}

The MLME has a high phenolic content which is known based on total phenolic content testing at the extract concentration of $500 \mu \mathrm{g} \mathrm{mL}{ }^{-1}$. The value of TPC obtained is $1849.716 \pm 7.567 \mathrm{mg}$ GAE$/ 100$ gram dry weight. Based on Balan et al. (2015), TPC values above $1000 \mathrm{mg}$ GAE/100 gram dry weight are classified into high TPC values.

Identification using TLC method was done to know the type of class of phenolic compounds contained in the MLME. The eluent used was chloroform: ethyl acetate and the solvent used was methanol: ethyl acetate. The use of eluent and solvent for TLC is the result of optimizing some eluents and solvents. The determination of eluent and solvent was also adjusted with quercetin as the comparative solution. The best results were obtained by using the chloroform: ethyl acetate (40:60) as an eluent and methanol: ethyl acetate $(60: 40)$ as a solvent. MLME separated into two spots i.e. yellow and green spots when viewed in visible light and two black spots under $254 \mathrm{~nm}$ UV light in Figure 1. Clearer results are shown after silica plate was exposed with ammonia vapor and seen under UV light at $254 \mathrm{~nm}$, each plate shows two spots that can be seen in Figure 2. The Rf value of extract and quercetin can be seen in Table 2 .

Table 2. Table of $\mathrm{Rf}$ value before and after exposure with ammonia vapor

\begin{tabular}{lcc}
\hline Condition & Rf extract & Rf quercetin \\
\hline Before exposing & 0.859 & 0.761 \\
After exposing & 0.872 & 0.775 \\
\hline
\end{tabular}

Note: $\mathrm{Rf}$ value of extract and quercetin was measured before and after exposing with ammonia vapor through calculating the eluent distance from the lower border of the silica plate.

\section{Antioxidant activity and cell viability}

Antioxidant activity was measured based on the \% inhibition of DPPH that can be seen in Table 1. Based on
Table $1, \mathrm{IC}_{50}$ value for antioxidant activity was $3.030 \mu \mathrm{g}$ $\mathrm{mL}^{-1}$. It showed high antioxidant activity because it is lower than $50 \mu \mathrm{g} \mathrm{mL}^{-1}$ (Hilmi et al. 2014).

The results of the cell viability test of 3T3 fibroblast cells to the MLME done using MTT method can be seen in Figure 3. Based on the data known, the extract did not show the cytotoxicity to $3 \mathrm{~T} 3$ fibroblast cells. The value of cytotoxicity was expressed in $\mathrm{IC}_{50}$ of $782.115 \mu \mathrm{g} \mathrm{mL} \mathrm{m}^{-1}$. $\mathrm{IC}_{50}$ values above $200 \mu \mathrm{g} \mathrm{mL}^{-1}$ show that the extract is not toxic to cells (Limtrakul et al. 2016). Based on $\mathrm{IC}_{50}$ values of antioxidant activity and cytotoxicity, the determination of concentrations of 5,10 , and $20 \mu \mathrm{g} \mathrm{mL}^{-1}$ can be done for subsequent experiments.

\section{Intracellular ROS level}

The intracellular ROS level is known through simple assay using modified NBT. The absorbance values obtained indicate intracellular ROS levels based on the interaction between NBT and intracellular ROS (Tunc et al. 2008).

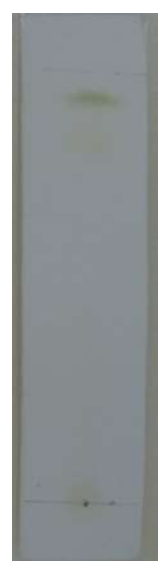

$\mathbf{A}$

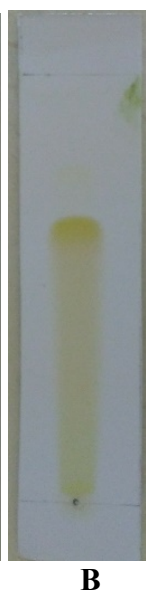

B

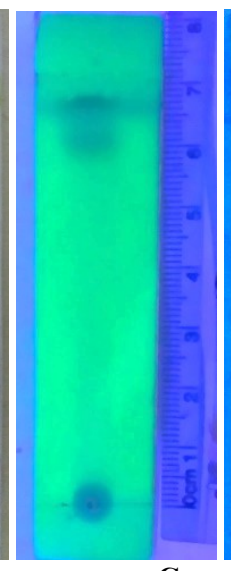

C

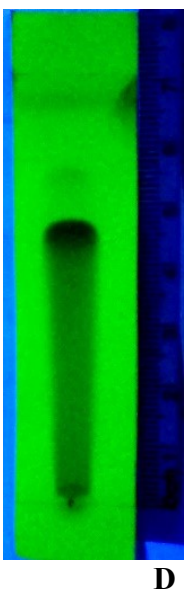

Figure 1. TLC results of MLME (A) and quercetin (B) on visible light. TLC results of MLME (C) and quercetin (D) under UV light at $254 \mathrm{~nm}$ before exposed with ammonia vapor

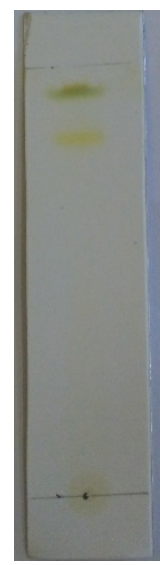

A

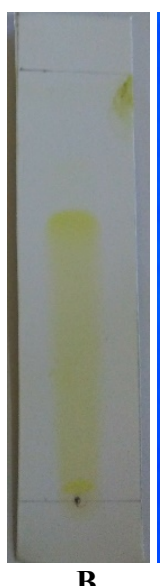

B

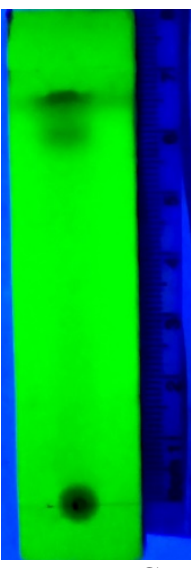

C

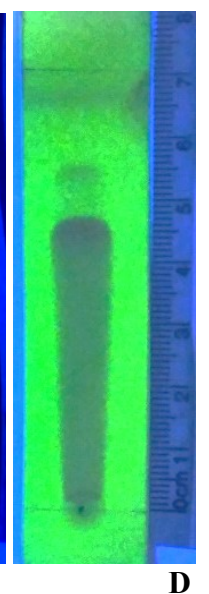

D
Figure 2. TLC results of MLME (A) and quercetin (B) on visible light. TLC results of MLME (C) and quercetin (D) under UV light at $254 \mathrm{~nm}$ after exposed with ammonia vapor 


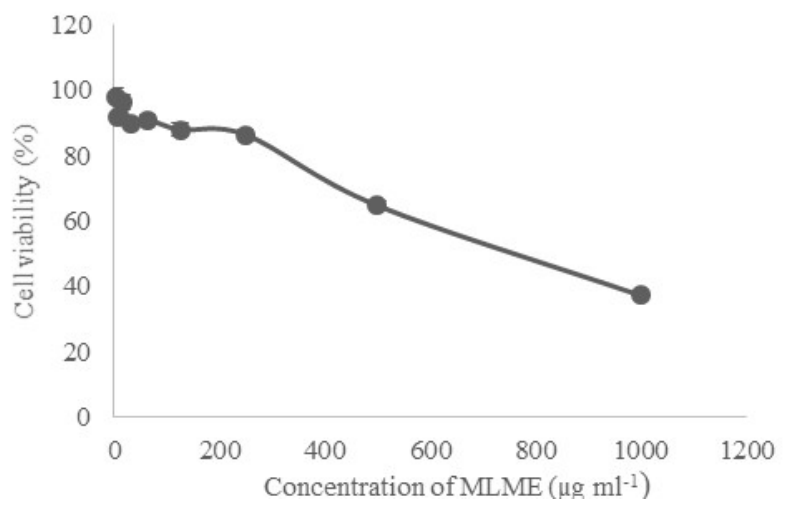

Figure 3. Effect of MLME on the $3 \mathrm{~T} 3$ fibroblast cells viability. The cells were treated with various concentrations of MLME (3.9 $-1000 \mu \mathrm{g} \mathrm{mL}^{-1}$ ) for 24 hours. The cells viability was determined with MTT assay.

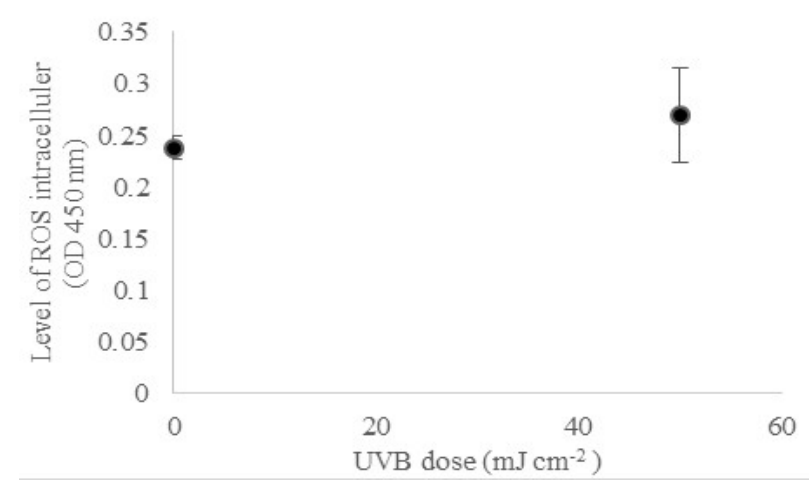

Figure 4. Effect of UVB exposure at a dose of $50 \mathrm{~mJ} \mathrm{~cm}^{-2}$ on the intracellular ROS levels. The two groups were analyzed by using one-way ANOVA followed by Tukey-Kramer post hoc test. Two groups showed difference in mean but not significant $(p>0.05)$.

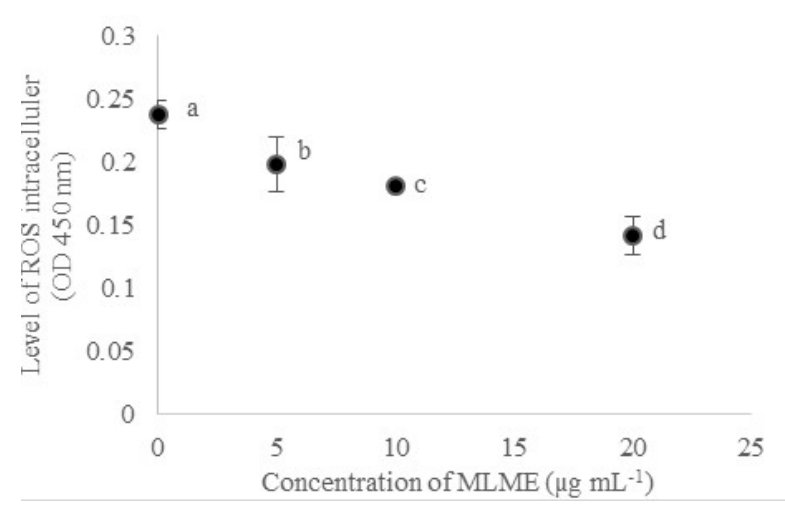

Figure 5. Effect of MLME with different concentrations $(0-20$ $\left.\mu \mathrm{g} \mathrm{mL} L^{-1}\right)$ on the intracellular ROS levels under normal condition. Values with different letter showed significant differences $(\mathrm{p}<$ 0.05 ) based on one-way ANOVA followed by Tukey-Kramer post hoc test.

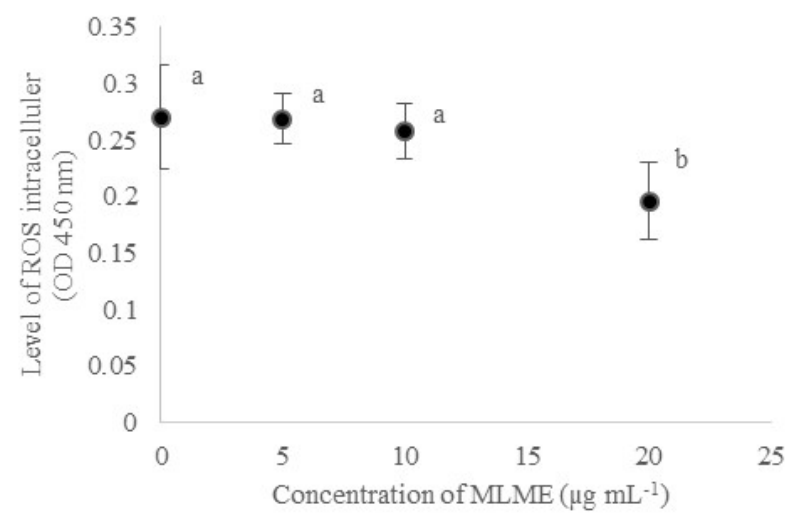

Figure 6. Effect of MLME with different concentrations (0 - 20 $\mu \mathrm{g} \mathrm{mL}{ }^{-1}$ ) on the intracellular ROS intracellular levels after exposured with UVB at a dose of $50 \mathrm{~mJ} \mathrm{~cm}^{-2}$. Values with different letter showed significant differences based on one-way ANOVA $(p>0.05)$ followed by Tukey-Kramer post hoc test

Giving extract to $3 \mathrm{~T} 3$ fibroblast culture under normal condition statistically significant to intracellular ROS level $(p<0.05)$ based on dose-dependent manner (Figure 5). The intracellular ROS level of fibroblast cells after administration of an MLME under oxidative stress condition showed a significant effect on the concentration of $20 \mu \mathrm{g} \mathrm{mL}^{-1}$ on the control of oxidative stress without extract. The results can be seen in Figure 6.

\section{Discussion}

Oxidative stress in this study was stimulated through

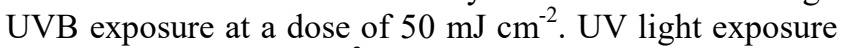
at a dose of $50 \mathrm{~mJ} \mathrm{~cm} \mathrm{~cm}^{-2}$ was statistically different in the mean but did not give a significant difference $(p>0.05)$. UV exposure can indirectly affect the production of ROS in greater quantities and ends in the aging process (Rinnerthaler et al. 2015). The results showed that the administration of MLME decreased intracellular ROS level in $3 \mathrm{~T} 3$ fibroblast cells under normal condition based on dose-dependent manner (Figure 5), while under oxidative stress condition showed significant influence at $20 \mu \mathrm{g} \mathrm{mL}^{-1}$ concentration on control without extract (Figure 6). Decreased ROS levels in 3T3 fibroblast cells under normal conditions and oxidative stress after administration of the MLME correlated polyphenol components measured on the TPC test (Bravo et al. 2017). Flavonoids are a group of phenol compounds identified through the TLC method. MLME had a similar Rf value with the quercetin comparative solution (Table 1) identified that in the MLME there was a compound similar to quercetin which is a flavonoid.

The decrease in intracellular ROS levels in this study is thought to be the effect of phenol compounds, especially flavonoids, which can act as direct scavengers and restore the balance of the endogenous antioxidant system of 3T3 fibroblast cells (Guerra-Araiza et al. 2013). The mechanism of MLME in reducing intracellular ROS still has not been able to be explained through this study, but Nakchat et al. (2014) study showed that the administration of Tamarin 
Seed Coat Extract (TSCE) containing phenolic and flavonoid compounds in CCD-1064Sk fibroblast cells reduces oxidative stress through increased GSH activity which is an endogenous antioxidant. The hydroxyl groups present in flavonoid compounds act as electron donors for ROS (Bosch et al. 2015), thus stabilizing ROS and reducing oxidative stress.

The ability of ROS scavenging of MLME was measured through DPPH radical scavenging activity which was expressed as $\mathrm{IC}_{50}$ values. $\mathrm{IC}_{50}$ values obtained from this study are consistent with the results of previous research (Zakaria et al. 2014a, b; Balan et al. 2015) that MLME has a very high antioxidant activity because it is lower than $50 \mu \mathrm{g} \mathrm{mL}^{-1}$. Based on Molyneux (2004) the lower the value of $\mathrm{IC}_{50}$, the higher the antioxidant activity. $\mathrm{IC}_{50}$ values are also used to express the toxicity of MLME to $3 \mathrm{~T} 3$ fibroblast cells. $\mathrm{IC}_{50}$ values obtained from MTT test of the MLME (Figure 3) showed a value above $200 \mu \mathrm{g} \mathrm{mL}$ ${ }^{1}$. Based on Limtrakul et al. (2016) the $\mathrm{IC}_{50}$ value above $200 \mu \mathrm{g} \mathrm{mL}^{-1}$ indicates that the extract is safe for subsequent experiments because it has low cytotoxicity.

This research concludes that MLME has an ability in reducing intracellular ROS levels causes it to potentially serve as a natural antioxidant source to combat oxidative stress. This potential allows M. calabura to be a potential source of antioxidants for anti-aging cosmetic products. Further research related to anti-aging potential of $M$. calabura needs to be done.

\section{ACKNOWLEDGEMENTS}

This research was done by private financial supports. Acknowledgments are conveyed to Integrated Laboratory, Sebelas Maret University, Surakarta, Indonesia which allowed the authors to do the works. We also would like to thank the Parasitology Department of Medical Faculty of Gadjah Mada University, Yogyakarta, Indonesia which encouraged the authors to do cell culture.

\section{REFERENCES}

Adrian A, Schoppmann K, Sromicki J, Brungs S, Wiesche M, Hock B, Kolanus W, et al. 2013. The oxidative burst reaction in mammalian cells depends on gravity. J Cell Commun Signal 1 (98): 1-20.

Balan T, Sani MHM, Ahmad SHM, Suppalah V, Mohtarrudin N, Zakaria ZA. 2015. Antioxidant and anti-inflammatory activities contribute to the prophylactic effect of semi-purified fractions obtained from the crude methanol extract of Muntingia calabura leaves against gastric ulceration in rats. J Ethnopharmacol 164: 1-15.

Bhattacharyya A, Chattopadhyay R, Mitra S, Crowe SE. 2014. Oxidative stress: an essential factor in the pathogenesis of gastrointestinal mucosal diseases. Physiol Rev 94: 329-354.

Bosch R, Philips N, Suarez-Perez JA, Juarranz A, Devmurari A, Chalensouk-Khaosaat J, Gonzalez S. 2015. Mechanisms of photoaging and cutaneous photocarcinogenesis, and photoprotective strategies with phytochemicals. Antioxidants 4: 248-268.

Bravo K, Duque L, Ferreres F, Moreno DA, Osorio E. 2017. Passiflora tarminiana fruits reduce UVB-induced photoaging in human skin fibroblasts. J Photochem Photobiol B 168: 78-88.
Freshney RI. 2010. Culture of Animal Cells: A Manual of Basic Technique and Specialized Applications 6th Edition. John Wiley \& Sons Inc New Jersey.

Guerra-Araiza C, Alvarez-Mejia AL, Sanchez-Torres S, Farfan-Garcia E., Mondragon-Lozano R, Pinto-Almazan R, Salgado-Ceballos H. 2013. Effect of natural exogenous antioxidants on aging and on neurodegenerative diseases. Free Radic Res 47 (6-7): 451-462.

Hilmi Y, Abushama MF, Abdalgadir H, Khalid A and Khalid H. 2014. A study of antioxidant activity, enzymatic inhibition and in vitro toxicity of selected traditional Sudanese plants with anti-diabetic potential. BMC Complement Altern Med 14: 149. DOI: 10.1186/1472-6882-14149.

Jadoon S, Karim S, Asad MHHB, Akram MR, Khan AK, Malik A, Chen, C, Murtaza G. 2015. Anti-aging potential of phytoextract loadedpharmaceutical cream for human skin cell longevity. Oxid Med Cell Longev 2015. DOI: 10.1155/2015/709628.

Jemli ME, Kamal R, Marmouzi I, Zerrouki A, Cherrah Y, Alaoui K. 2016. Radical-scavenging activity and ferric reducing ability of Juniperus thurifera (L.), J. oxycedrus (L.), J. phoenicea (L.) and Tetraclinis articulata (L.). Adv Pharmacol Sci 2016. DOI: $10.1155 / 2016 / 6392656$

Lim TK. 2012. Muntingia calabura. Edible Medicinal and Non-Medicinal Plants 3: 486-492.

Limtrakul P, Yodkeeree S, Thippraphan P, Punfa W, Srisomoonm J. 2016. Anti-aging and tyrosinase inhibition effects of Cassia fistula flower butanolic extract. BMC Compl Altern Med 16: 497. DOI 10.1186/s12906-016-1484-3.

Mahmood ND, Nasir NLM, Rofiee MS, Tohid SFM, Ching SM, Teh LK, Salleh MZ, Zakaria ZA. 2014. Muntingia calabura: A review of its traditional uses, chemical properties, and pharmacological observations. Pharm Biol 52 (12): 1598-1623.

Molyneux, P. 2004. The use of the stable free radical diphenyl picrylhydrazyl (DPPH) for estimating antioxidant activity. Songklanakarin J Sci Technol 26 (2): 211-219.

Nakchat O, Nalinratana N, Meksuriyen D, Pongsamart S. 2014. Tamarind seed coat extract restore reactive oxygen species through attenuation of glutathione level and antioxidant enzyme expression in human skin fibroblast in response to oxidative stress. Asian Pac J Trop Biomed 4 (5): 379-385

Nasir NLMd, Kamsani NE, Mohtarrudin N, Othman F, Tohid SFMd, Zakaria ZA. 2017. Anticarcinogenic activity of Muntingia calabura leaves methanol extract against the azoxymethane-induced colon cancer in rats involved modulation of the colonic antioxidant system partly by flavonoid. Pharm Biol 55 (1): 2102-2109.

Pisoschi AM, Pop A. 2015. The role of antioxidants in chemistry of oxidative stress: A review. Eur J Med Chem 97: 55-74.

Poprac P, Jomova K, Simunkova M, Kollar V, Rhodes CJ, Valko M. 2017. Targeting free radical in oxidative stress-related human diseases. Trends Pharmacol Sci 38 (7): 592-607.

Rinnerthaler M, Bischof J, Streubel MK, Trost A, Richter K. 2015. Oxidative stress in aging human skin. Biomolecules 5: 545-589.

Sarangarajan R, Meera S, Rukkumani R, Anuradha G. 2017. Antioxidants: friend or foe. Asian Pac J Trop Med 10 (12): 11111116.

Singleton VL, Orthofer R, Lamuela-Raventos RM. 1999. Analysis of total phenols and other oxidation substrates and antioxidant by means of Folin-Ciocalteu reagent. Methods Enzymol 299: 152-178.

Tunc O, Thompson J, Tremellen K. 2008. Development of the NBT assay as a marker of sperm oxidative stress. Intl J Androl 33 (2010): 13-21.

Valko M, Jomova K, Rhodes CJ, Kuca K, Musilek K. 2016. Redox-and non-redox-mental-induced formation of free radicals and their role in human disease. Arch Toxicol 90: 1-37.

Zakaria ZA, Mohamed AM, Jamil NSM, Rofiee MS, Hussain MK, Sulaiman MR, Teh LK, Salleh MZ. 2011. In vitro antiproliferative and antioxidant activities of the extracts of Muntingia calabura leaves. Am J Chin Med 39 (1): 183-200.

Zakaria ZA, Sani MHM, Cheema MS, Kader AA, Teh LK, Salleh MZ. 2014a. Antinociceptive activity of methanolic extract of Muntingia calabura leaves: further elucidation of the possible mechanisms. BMC Compl Altern Med 14: 63. DOI: 10.1186/1472-6882-14-63.

Zakaria ZA, Balan T, Suppalan V, Ahmad S, Jamaludin F. 2014b. Mechanism(s) of action involved in the gastroprotective activity of Muntingia calabura. J Ethnopharmacol 151 (2014): 1184-1193. 